ISSN 2723-7583 (Online)

\title{
STOK DAN SERAPAN KARBON PADA JENIS MANGROVE YANG BERBEDA (Rhizophora stylosa, Avicennia marina dan Bruguierra gymnorrhiza) DI PERAIRAN TUBAN
}

STOCK CARBON IN THE TYPE OF DIFFERENT (Rhizophora stylosa, Avicennia marina dan Bruguierra gymnorrhiza) in TUBAN COAST

\author{
Choridina Kareninsekar ${ }^{1}$ dan Insafitri ${ }^{2}$ \\ ${ }^{1}$ Mahasiswa Program Studi IImu Kelautan, Jurusan Kelautan dan Perikanan Fakultas Pertanian, \\ Universitas Trunojoyo Madura \\ ${ }^{2}$ Program Studi IImu Kelautan, Jurusan Kelautan dan Perikanan Fakultas Pertanian, Universitas \\ Trunojoyo Madura
}

Corresponding author e-mai: Choridinakareningsekar@gmail.com

Submitted: 16 June 2020 / Revised: 26 August 2020 / Accepted: 26 August 2020

http://doi.org/ 10.21107/juvenil.v1i2.7576

\begin{abstract}
Mangrove is one of special plant in tropical forest which has ability to flourish in the river area or usually call estuari area. Mangrove has benefit as absorbing carbon dioxide, which is the process of photosynthesis change inorganic carbon (CO2)into organic carbon in the form of vegetation material. Tuban regency is one of regency which located in East Java which has coastline length around 65 $\mathrm{km}$, and has distribution of mangrove forest 120,40 Ha. The aim of this research to know about amount of uptake absorption carbon dioxide (CO2) on type of mangrove which different in Tuban. The study was conducted on the coast of Tuban covering mangrove center in Mangrove Center Tuban, Jenu Kabupaten Tuban with use three research points and every point does three times repetitions. This research was conducted on November 2018. Technique of collecting data used decstructive method and calculation of data include water content value, ash content, carbon and uptake of carbon dioxide in basic laboratory, faculty of agriculture. Based on the results was obtained mangrove which have amount uptake highest carbon dioxide is mangrove with type Rhizophora stylosa with uptake value CO2 as much as 738,5 gram CO2/1000 gr tree, and highest uptake available in part of stem as much as 163,62 gram CO2/1000 gr tree.The value of uptake carbondioxide the highest number two there are the types of Bruguierra gymnorrhiza as much as 713,65 gram CO2/ $1000 \mathrm{gr}$ tree with the highest absorption which found on the leaf as much as 160,18 gram CO2/1000gr tree and the lowest absorption that is Avicennia marina as much as 700,93 with the highest absorption also found on leaf as much as $147,33 \mathrm{gr} \mathrm{CO2/1000} \mathrm{gr}$ tree.
\end{abstract}

Keywords: Stock, carbon, Mangrove and Tuban Coast.

\begin{abstract}
ABSTRAK
Mangrove merupakan suatu tumbuhan khas pada hutan tropis yang memiliki kemampuan tumbuh subur di daerah muara sungai atau disebut dengan daerah estuari. Mangrove memiliki manfaat sebagai penyerap karbondioksida, dimana proses fotosintesis mengubah karbon anorganik $\left(\mathrm{CO}_{2}\right)$ menjadi karbon organik dalam bentuk bahan vegetasi. Kabupaten Tuban salah satu kabupaten yang berada di propinsi Jawa Timur dengan memiliki panjang garis pantai sekitar65 km, dan memiliki sebaran hutan mangrove 120,40 Ha. Penelitian bertujuan mengetahui jumlah serapan karbondioksida $\left(\mathrm{CO}_{2}\right)$ pada jenis mangrove yang berbeda diperairan Tuban.Penelitian dilakukan di pesisir Tuban mencakup kawasan pusat mangrove di Mangrove Center Tuban, Jenu Kabupaten Tuban dengan menggunakan tiga titik penelitian dan masing masing titik dilakukan tiga kali pengulangan. Penelitian dilakukan pada bulan November 2018. Metode pengambilan data menggunakan metode dekstruktif dan perhitungan data meliputi nilai kadar air, kadar abu ,karbon dan serapan karbondioksida di Laboratorium Dasar Fakultas Pertanian. Berdasarkan hasil yang diperoleh mangrove yang memiliki total serapan karbondioksida tertinggi adalah mangrove jenis Rhizophora stylosa dengan nilai serapan $\mathrm{CO}_{2}$ sebesar 738,5 gram $\mathrm{CO}_{2} / 1000 \mathrm{gr}$ pohon, yang penyerapan tertinggi terdapat pada
\end{abstract}


Juvenil, 1(2), 220-226, (2020)

bagian batang sebesar 163,62 gr $\mathrm{CO}_{2} / 1000 \mathrm{gr}$ pohon. Nilai serapan karbondioksida tertinggi kedua terdapat pada jenis Bruguierra gymnorrhiza sebesar 713,65 gr $\mathrm{CO}_{2} / 1000 \mathrm{gr}$ pohon dengan penyerapan tertinggi terdapat pada bagian daun sebesar $160,18 \mathrm{gram} \mathrm{CO}_{2} / 1000 \mathrm{gr}$ pohon dan yang memiliki penyerapan $\mathrm{CO}_{2}$ terendah yaitu Avicennia marina sebesar 700,93 gr CO2/ $1000 \mathrm{gr}$ pohon, dengan peneyerapan tertinggi juga terdapat pada daun sebsar 147,33 $\mathrm{gr} \mathrm{CO}_{2} / 1000 \mathrm{gr}$ pohon.

Kata Kunci :Stok, Karbon, Mangrove dan Perairan Tuban

\section{PENDAHULUAN}

Mangrove merupakan tanaman yang memiliki peranan sebagai salah satu agen penyerap karbondioksida (CO2) yang berasal dari udara sehingga berpengaruh terhadap perubahan iklim. Mangrove mampu menyimpan karbon lebih dari hampir keseluruhan hutan lainnya di bumi (Daniel et al., 2011). Vegetasi mangrove memiliki kandungan karbon (C) yang diperkirakan memiliki erat hubungannya dengan besarnya biomassa suatu pohon. Ekosistem mangrove di Indonesia diperkirakan memiliki kemampuan menyerap karbon diudara mencapai 67,7 meter $\mathrm{CO} 2$ per tahun (Sadelie et al., 2012). Kerusakan hutan mangrove yang sering terjadi pada hal ini menimbulkan pelepasan karbondioksida (CO2) ke atmosfer bumi menghasilkan jumlah yang banyak, setingkat dengan adanya kerusakan hutan yang terjadi (Munari, 2011). Setiap tahun hutan mangrove dapat menyerap 42 juta ton karbon di udara atau setara dengan emisigas karbon dari 25 juta mobil (Ardianto, 2011).

Kabupaten Tuban adalah salah satu kabupaten yang berada di propinsi Jawa Timur dengan memiliki panjang garis pantai sekitar $65 \mathrm{~km}$. Potensi kota Tuban dengan sebutan PANTURA memiliki ketertarikan tersendiri untuk dijadikan sebagai tempat wisata. kawasan pesisir Tuban juga memiliki kawasan hutan mangrove salah satunya berada di kawasan konservatif mangrove yaitu Mangrove Center Tuban yang terletak di desa Jenu, memiliki sebaran hutan mangrove 120,40 Ha (BPS Tuban, 2013). Berdasarkan hasil analisa vegetasi mangrove di kawasan pesisir Tuban yang mencakup kawasan Mangrove Center Tuban. Perbedaan fisik dari masing masing jenis menjadikan setiap jenis mangrove memiliki kapasitas karbon yang berbeda.

Pengambilan sampel uji pada jenis mangrove yang berbeda bertujuan untuk mengetahui kontribusi pada jenis mangrove guna melakukan penyerapan $\mathrm{CO} 2$ yaitu dengan menganalisis serapan karbon masing masing jenis mangrove. Hasil penelitian ini dimaksudkan untuk memberikan informasi mengenai penyerapan karbon dari beberapa jenis mangrove yang berbeda guna untuk revegetasi. Mengingat karbon merupakan salah satu unsur yang utama dalam pembentukan bahan organik termasuk makhluk hidup (Munari, 2011).

Hutan Mangrove memiliki manfaat dan fungsi yang sangat penting dalam ekosistem hutan, air, dan lingkungan. Mangrove juga bermanfaat sebagai penyerap karbon, dimana proses fotosintesis mengubah karbon anorganik (CO2) menjadi karbon organik dalam bentuk bahan vegetasi. Pemanasan global merupakan salah satu isu di dunia saat ini, ditandai dengan adanya peristiwa meningkatnya suhu bumi yang terkait langsung dengan gas-gas rumah kaca. Kontributor pemanasan global seperti gas karbon dioksida (CO2) dan metana $(\mathrm{CH} 4)$ (Soemarwoto, 1998).

Biomassa merupakan total jumlah dari bahan organik yang berada diatas tanah pada suatu pohon. Komponen pada pengukuran dugaan biomassa biasanya berada diatas tanah karena merupakan bagian besar dari berat jumlah keseluruhan total biomassa. Karbon karbon dihutan yang utama terdiri dari biomassa organisme hidup, organisme mati, tanah dan kayu atau pohon mati. Karbon merupakan suatu unsur pembentuk bahan organik. Sebagian besar mahkluk hidup merupakan bagian dari karbon. Secara alami karbon banyak tersimpan di dalam darat dan laut daripada diatmosfer Karbon merupakan unsur alam yang memiliki lambang " $\mathrm{C}$ " yang memiliki nilai atom sebesar 12 (Munari, 2011). Dalam bumi karbon tersimpan dalam bentuk makhluk hidup, bahan organik mati dan sedimen. Salah satu penghasil karbon terbanyak di bumi diperoleh dari hutan.

Kondisi hutan yang banyak mengalami kerusakan berdampak pada pelepasan karbondioksida (CO2) juga semakin banyak, hal demikian setingkat dengan kerusakan hutan yang terjadi (Munari, 2011). Menurut Brown (1996) hampir 40\% dari biomassa pohon adalah karbon, yang dimana pohon melalui proses fotosintesis menyerap karbon melalui proses fotosintesis yang menyerap karbondioksidadari atmosfer, kemudian mengubahnya menjadi karbon organik dan 
Kareninsekar dan Insafitri, Stok dan Serapan Karbon

menyimpannya dalam biomassa tubuhnya seperti dalam batang, daun, akar, umbi, buah dan lainnya. Salah satu cara untuk mengetahui simpanan karbon adalah dengan menghitung biomassa dari tumbuhan tersebut.

\section{MATERI DAN METODE}

Penelitian dilakukan pada bulan November 2018 dikawasan pesisir Tuban yang mencakup daerah konservatif Mangrove Center Tuban, di Kecamatan Jenu kabupaten Tuban. Kawasan ini dipilih karena dianggap mewakili wilayah studi karena memiliki jenis mangrove yang paling dominan. Pengambilan sampel untuk setiap titik dilakukan tiga kali pengulangan Gambar 1. merupakan peta lokasi penelitian. Berdasarkan hasil pengamatan lapang ditemukan tiga jenis mangrove yaitu Avicennia marina, Rhizophora stylosa dan Bruguierra gymnorrhiza.
Data tersebut didapatkan berdasarkan hasil observasi awal dan informasi dari diskusi dengan Ketua Mangrove Center Tuban. Pengovenan sampel dilakukan di Laboratorium Rekayasa Proses dan Bioindustri Progam Studi Teknologi Industri Pertanian, Fakultas Pertanian, Universitas Trunojoyo Madura. Pengovenan dilakukan pada suhu $70^{\circ} \mathrm{C}$ selama 48 dan kemudian dilanjutkan dengan melakukan pengabuan (furnace) pada suhu $450^{\circ} \mathrm{C}$ selama 5 jam di Laboratorium Dasar Universitas Trunojoyo Madura dalam mengetahui nilai kadar abu untuk mengetahui kandungan karbon dan serapan CO2. Metode penelitian ini menggunakan metode berupa metode dekstruktif dengan pengambilan sampel 3 pohon sebanyak tiga jenis mangrove yang berbeda (Rhizophora stylosa, Avicennia marina dan Bruguierra gymnorrhiza).

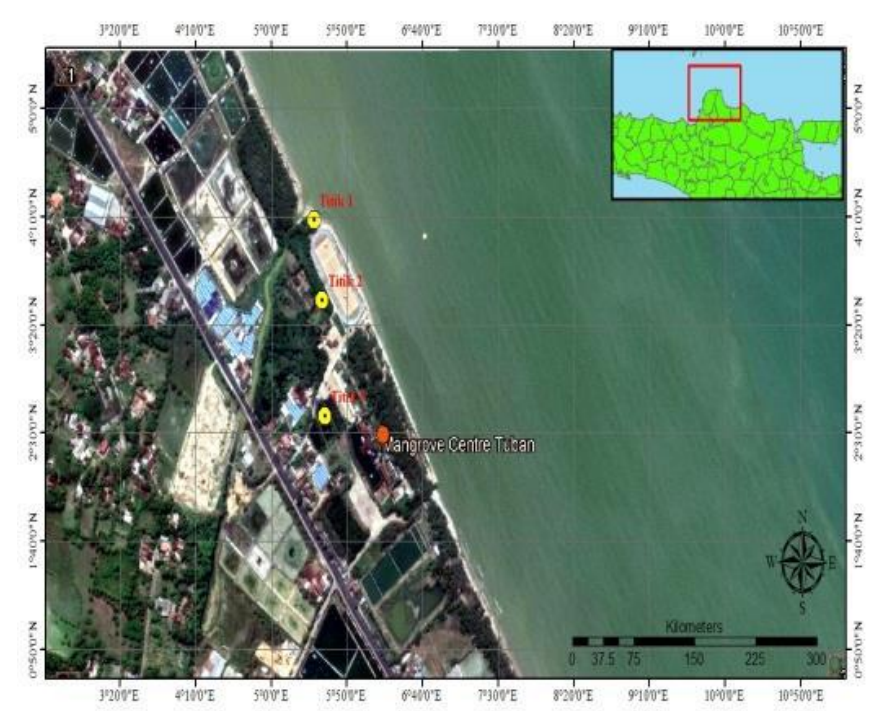

Gambar 1. Peta Lokasi Penelian

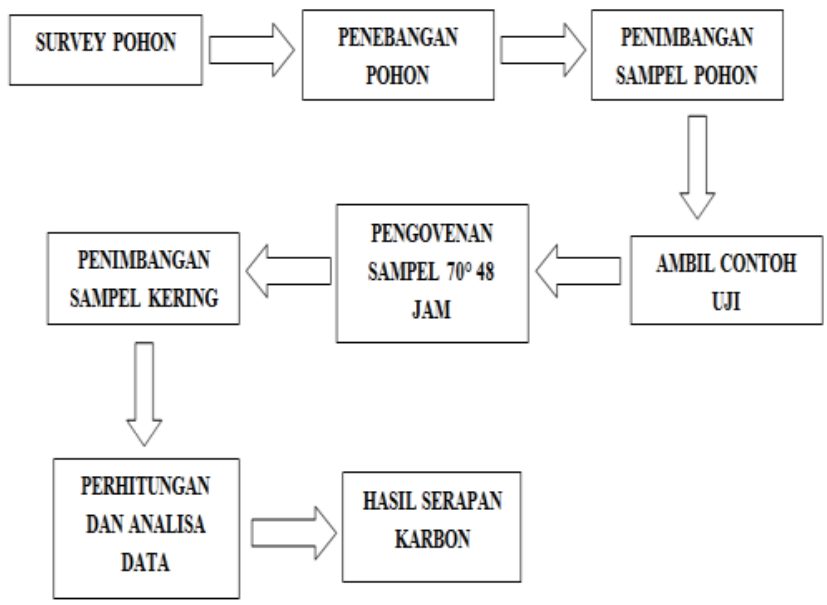

Gambar 2. Alur penelitian 
Juvenil, 1(2), 220-226, (2020)

Pengolahan Data

Kadar air

$$
\% \text { Kadar Air }=\frac{(A-B)}{A} \times 100 \%
$$

Keterangan :

kadar air (\%)

$\%$ Kadar Air = Nilai presentasi

$$
\begin{array}{ll}
\mathrm{A} & =\text { Berat basah sampel } \\
\mathrm{B} & =\text { Berat kering sampel }
\end{array}
$$

Biomassa

$$
\mathrm{Bo}=\frac{\mathrm{Bks} \times \mathrm{Bbt}}{\mathrm{Bbs}}
$$

Keterangan:

$$
\begin{array}{ll}
\text { Bo } & =\text { berat bahan organik (gram) } \\
\text { Bks } & =\text { berat kering contoh(gram) } \\
\text { Bbt } & =\text { berat basah total (gram) } \\
\text { Bbs } & =\text { berat basah contoh, (gram). }
\end{array}
$$

\section{Kadar Abu}

$$
\% \mathrm{Kadar} \mathrm{Abu}=\frac{(z-\mathrm{X})}{\mathrm{Y}} \times 100 \%
$$

Keterangan :

$\mathrm{X}=$ Berat Cawan

$Y=$ Berat Kering Sampel

Z = Berat Sampel setelah di Oven + Cawan

\section{Kandungan Karbon}

Karbon $_{\text {(gram) }}=\left(\right.$ Berat Kering $_{\text {(gram) }}-$ Kadar Abu $\left._{\text {(gram) }}\right)$
Perhitungan Serapan Karbondioksida $\left(\mathrm{CO}_{2}\right)$

$$
\mathrm{CO}_{2}(\mathrm{~g})=3,67 \times \text { Kandungan Karbon }
$$

Keterangan :

$\mathrm{Mr}=$ Molekul Relatif

$\mathrm{CO}_{2}=$ Jumlah Serapan Karbondioksida

$\mathrm{Ar}=$ Atom Relatif

\section{HASIL DAN PEMBAHASAN}

Pada tabel perhitungan serapan karbondioksida mangrove terlihat bahwa mangrove jenis Avicennia marina memiliki penyerapan karbon terendah yaitu sebesar 700,93 gram CO2/50gram pohon. Sedangkan Bruguierra gymnorrhiza merupakan mangrove yang menyerap karbon tertinggi kedua di udara setelah Rhizophora stylosa, yaitu sebesar 713,65 gram CO2/1000 gram pohon dan nilai tertinggi terdapat pada bagian batang 163,62 gram CO2/1000 gram pohon. Hasil tersebut sama dengan penelitian sebelumnya oleh Akbar (2015) yang menunjukkan bahwa potensi serapan karbon yang paling besar juga terdapat pada bagian batang jenis Rhizophora sp., yaitu sebesar 194,58 gram CO2/gram pohon dengan total penyerapan karbon

\begin{tabular}{|c|c|c|c|c|}
\hline Jenis Mangrove & Bagian & $\begin{array}{l}\text { Biomassa } \\
\text { Mangrove } \\
\text { (gr)/1000gr } \\
\text { pohon }\end{array}$ & $\begin{array}{l}\text { Karbon } \\
\text { Mangrove } \\
\text { (gr)/1000gr } \\
\text { pohon }\end{array}$ & 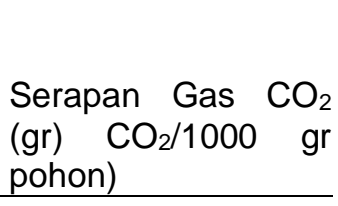 \\
\hline \multirow{5}{*}{ Avicennia marina } & Propagul & 192,24 & 36,54 & 134,13 \\
\hline & Akar Dalam & 198,15 & 38,69 & 142 \\
\hline & Batang & 205,54 & 38,89 & 142,73 \\
\hline & Daun & 212,66 & 40,14 & 147,33 \\
\hline & Akar Luar & 193,36 & 36,71 & 134,75 \\
\hline \multirow{5}{*}{ Rhizophora stylosa } & Propagul & 210,06 & 40,53 & 148,75 \\
\hline & Akar Dalam & 194,18 & 38,26 & 140,43 \\
\hline & Batang & 229,67 & 44,58 & 163,62 \\
\hline & Daun & 216,99 & 41,99 & 154,1 \\
\hline & Akar Luar & 159,99 & 32,52 & 119,34 \\
\hline
\end{tabular}
sebesar 397,53 gram CO2/1000 gram pohon. Hasil tersebut lebih kecil dibandingkan dengan hasil penelitian iniyang menghasilkan nilai total serapan karbon tertinggi pada Rhizophora stylosa yaitu sebesar 726,269 gram CO2/1000 gram pohon. Hal ini dipengaruhi karena adanya perbedaan tinggi dari sampel pohon mangrove.

Tabel 1. Nilai Kandungan Biomassa, Karbon Biomassa dan Serapan Karbondioksida 


\begin{tabular}{lllll}
\hline & Propagul & 200,57 & 39,68 & 145,62 \\
Bruguierra & Akar Dalam & 188,9 & 36,05 & 132,31 \\
gymnorrhiza & Batang & 198,99 & 38,84 & 142,54 \\
& Daun & 223,77 & 43,64 & 160,18 \\
& Akar Luar & 190,76 & 36,23 & 132,98 \\
\hline
\end{tabular}

Meningkatnya serapan gas $\mathrm{CO} 2$ dalam hal ini terjadi karena serapan gas karbondioksida (CO2) memiliki hubungan positif antara kandungan karbon (Sadelie et al., 2012). Dengan demikian dapat diartikan bahwa serapan gas karbon dioksida (CO2) akan besar apabila total kandungan karbon dan biomassa yang dimiliki tumbuhan juga ikut besar begitu pula sebaliknya. Kemampuan tumbuhan dalam menyerap $\mathrm{CO} 2$ dipengaruhi oleh beberapa faktor seperti suhu, sinar matahari, ketersedian air, luas keseluruhan daun, umur dan dan fase pertumbuhan.

Pertumbuhan pohon melalui hasil fotosintesis kemudian digunakan oleh tumbuhan untuk melakukan pertumbuhan ke arah horisontal dan vertikal. Secara umum hutan dengan new growth (terutama pohon yang sedang berada dalam fase pertumbuhan) mampu menyerap $\mathrm{CO} 2$, sedangkan hutan dewasa dengan pertumbuhan yang kecil menahan dan menyimpan persedian karbon tetapi Berdasarkan tabel Hasil Uji Test Of Homogenity of Variances Avicennia marina, Rhizhophora stylosa dan Bruguierra gymnorrhiza menunjukkan hasil bahwa sig > 0,05 yang berarti data penyerapan karbon pada ketiga jenis mangrove homogen, sehingga asumsi homogenitas dalam uji One Way Anova terpenuhi tidak menyerap CO2 (Sadelie et al., 2012).

Tabel 2. Uji Test of Homogenity of Variances

\begin{tabular}{|l|l|l|l|}
\hline Levene Statistic & df1 & df2 & Sig. \\
\hline 2.570 & 2 & 6 & .156 \\
\hline
\end{tabular}

Sedangkan pada tabel 3 mengenai hasil uji output Anova dapat diketahui diketahui nilai sig sebesar 0,040,yang menyatakan bahwa disimpulkan bahwa rata rata serapan karbon ketiga jenis mangrove tersebut berbeda nilai tersebut $<0,05$. Sehingga dapat secara signifikan.

Tabel 3. Hasil Uji One Way Anova Serapan Karbon Avicennia marina, Bruguierra gymnorrhiza, Rhizophora stylosa

\begin{tabular}{|l|l|l|l|l|l|}
\cline { 2 - 6 } Serapan Karbon & & & & & \\
\hline & Sum of Squares & df & Mean Square & F & Sig. \\
\hline Between Groups & 38.513 & 2 & 19.256 & 5.775 & .040 \\
Within Groups & 20.007 & 6 & 3.334 & & \\
Total & 58.519 & 8 & & & \\
\hline
\end{tabular}

Tabel 4. Hasil Uji Kesamaan Rata-rata Serapan Karbon Avicennia marina, Bruguierra gymnorrhiza, Rhizophora stylosa

Serapan Karbon

Tukey HSD

\begin{tabular}{|c|c|c|c|}
\hline \multirow[b]{2}{*}{ Jenis Mangrove } & \multirow[b]{2}{*}{$\mathrm{N}$} & \multicolumn{2}{|c|}{ Subset for alpha $=0.05$} \\
\hline & & 1 & 2 \\
\hline Avicennia marina & 3 & 139.6667 & \\
\hline Bruguierra gymnorrhiza & 3 & 142.0000 & 142.0000 \\
\hline Rhizophora stylosa & 3 & & 144.6667 \\
\hline Sig. & & .287 & .213 \\
\hline
\end{tabular}


Juvenil, 1(2), 220-226, (2020)

Serapan Karbon

Tukey HSD

\begin{tabular}{|l|l|l|l|}
\hline & & \multicolumn{3}{|l|}{ Subset for alpha $=0.05$} \\
\cline { 3 - 4 } Jenis Mangrove & $\mathrm{N}$ & 1 & 2 \\
\hline Avicennia marina & 3 & 139.6667 & \\
Bruguierra gymnorrhiza & 3 & 142.0000 & 142.0000 \\
Rhizophora stylosa & 3 & & 144.6667 \\
Sig. & & .287 & .213 \\
\hline
\end{tabular}

Means for groups in homogeneous subsets are displayed.

Pada subset 1 terdapat data serapan karbon Avicennia marina dan Bruguierra gymnorrhiza. Artinya rata rata penyerapan kedua mangrove tersebut tidak mempunyai perbedaan yang signifikan. Dengan kata lain, rata rata penyerapan karbon Avicennia marina dan Bruguierra gymnorrhiza adalah sama. Pada Subset 2 diketahui data penyerapan karbon Bruguierra gymnorrhiza dan Rhizophora stylosa. Artinya rata rata penyerapan karbon kedua jenis mangrove tersebut mempunyai perbedaan yang signifikan. Dengan kata lain, rata rata penyerapan karbon Bruguierra gymnorrhiza dan Rhizophora stylosa adalah sama. Sehingga dapat disimpulkan bahwa dalam riset eksperimen ini hanya rata rata Avicennia marina dan Rhizophora stylosa yang berbeda. Nilai tertinggi penyerapan karbon terdapat pada Rhizophora stylosa dan penyerapan terendah terdapat pada Avicennia marina.

Tabel 5. Nilai Parameter Pertumbuhan Mangrove

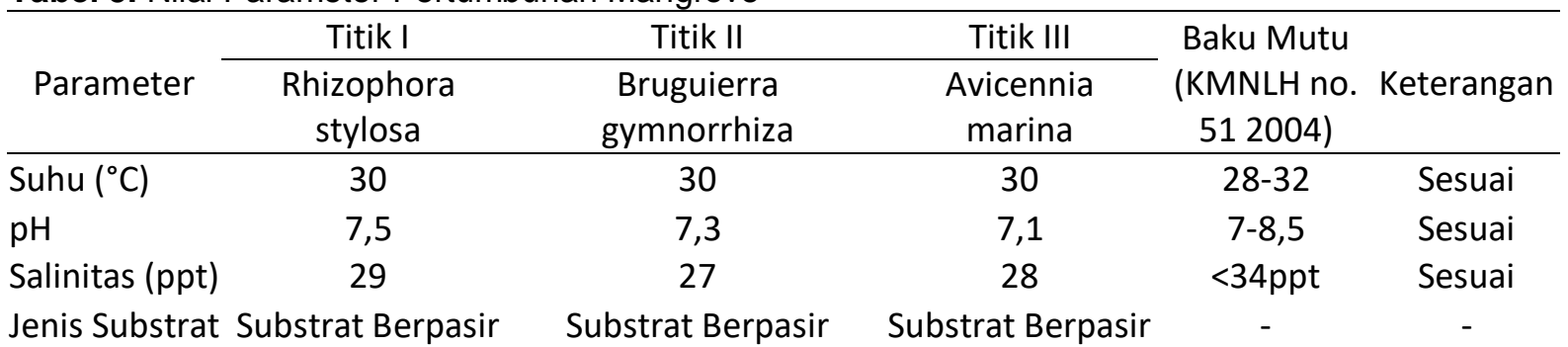

Nilai parameter di Perairan Mangrove Center Tuban berdasarkan tabel 4.5 tidak menunjukkan nilai yang bervariasi pada setiap titik. Hal ini mengindikasikan bahwa karakteristik fisika kimia perairan tersebut tidak jauh berbeda. Berdasarkan penelitian sebelumnya oleh Syarifah dan Ledhyane (2015) menyebutkan bahwa salinitas di perairan Mangrove Center Tuban 28,98 ppt, sedangkan hasil pengukuran rata rata salinitas penulis menunjukkan angka sebesar 28,66 ppt. Nilai salinitas tersebut sesuai dengan nilai Standar Baku Mutu menurut Keputusan Menteri Negara.

Lingkungan Hidup nomer 51 tahun 2004, yang menyatakan bahwa nilai salinitas untuk mangrove berkisar 0-34 ppt. Suhu di perairan Mangrove Center Tuban menunjukkan nilai yang sama di ketiga titik pengambilan sampel yaitu sebesar $30^{\circ} \mathrm{C}$. Nilai suhu tersebut sesuai dengan nilai Standar Baku Mutu menurut Keputusan Menteri Negara Lingkungan Hidup nomer 51 tahun 2004, yang menyatakan bahwa suhu yang cocok untuk pertumbuhan mangrove optimal berkisar $28-32^{\circ} \mathrm{C}$.

Hasil pengukuran $\mathrm{pH}$ sedimen yang ditunjukkan pada tabel 4.5 menunjukkan nilai rata rata $\mathrm{pH}$ sebesar 7,3 . Nilai $\mathrm{pH}$ terbesar pada titik I yaitu jenis Rhizophora stylosa sebesar 7,5 sedangkan nilai $\mathrm{pH}$ terendah pada titik III yaitu jenis Avicennia marina sebesar 7,1 . Nilai $\mathrm{pH}$ tersebut sesuai dengan nilaiStandar Baku Mutu menurut Keputusan Menteri Negara Lingkungan Hidup nomer 51 tahun 2004, yang menyatakan bahwa $\mathrm{pH}$ optimal untuk pertumbuhan mangrove berkisar 7-8,5.

Mangrove dari laut ke arah darat akan membentuk zonasi mangrove. Menurut Bengen (2004) menyebutkan bahwa padadaerah yang berhadapan dengan laut disebut zona mangrove terbuka dengan substrat pasir berlumpur ditumbuhi oleh 
spesies Sonnereatia alba, Rhizophora stylosa dan Xylocarpus granatum. Pernyataan tersebut memperkuat adanya hasil penelitian penulis bahwa di zona depan dari arah laut pada titik I ditemukan mangrove Rhizophora stylosa. Hal tersebut mengindikasikan bahwa pertumbuhan mangrove juga dipengaruhi oleh zona dan substrat yang mengandung berpasir, seperti ditunjukkan pada tabel 4.5. Mangrove dari arah laut menuju kedarat pada titik II yaitu daerah dekat tambak ditemukan mangrove Bruguierra gymnorrhiza dengan substrat juga berpasir tapi seperti berlumpur padat, karena tidak dipengaruhi adanya pasang surut air laut. Selanjutnya di titik III ditemukan mangrove Avicennia marina dengan menempati kawasan bersubstrat berpasir sama sepertiketiga jenis mangrove lainnya. Berdasarkan hasil penelitian diketahui bahwa substrat di perairan Tuban untuk pertumbuhan mangrove diindikasikan memiliki jenis substrat berpasir. Hal ini bertentangan dengan penelitian sebelumnya oleh Bengen (2004), yang menjelaskan bahwa pada zona yang berhadapan dengan laut akan didominasi oleh Sonneratia atau Avicennia sp. Sedangkan pada hasil penelitian, mangrove Avicennia marina ditemukan di zona paling belakang dengan substrat berlumpur.

\section{Kesimpulan}

\section{KESIMPULAN DAN SARAN}

Berdasarkan hasil penelitian yang dilakukan mengenai Stok Karbon di Perairan Tuban yang meliputi Kawasan Mangrove Center Tuban, dapat disimpulkan bahwa rata rata penyerapan karbon dari ketiga jenis mangrove yaitu Avicennia marina, Bruguierra gymnorrhiza dan Rhizophora stylosa menghasilkan nilai yang berbeda secara signifikan.

Diantara ketiga jenis mangrove yang memiliki nilai stok dan serapan karbon tertinggi, adalah Rhizophora stylosa dengan nilai terbesar di bagian batang.

\section{Saran}

Penelitian lanjutan mengenai pendugaan stok karbon dengan menggunakan metode non dekstruktif sampling (persamaan allometrik) diperlukan guna menghitung seberapa banyak jumlah serapan karbon dan simpanan karbon secara menyeluruh di kawasan hutan mangrove pada daerah konservasi Mangrove Center Tuban, Kecamatan Jenu, Kabupaten Tuban.

\section{DAFTAR PUSTAKA}

Achmadi, S.S.1(990). Diktat Kimia Kayu. Bogor : Pusat Antar Universitas, Institut

Ardianto, Tufik. (2011). Mangrove sebagai penangkap karbon, pendingin udara serta penahantsunami. Diakses dari www. Survey pemetaan. blogspot. com .pada tanggal 7 Oktober 2018

Brown. (1996). Guidelines for inventory and monitoring carbon offsets in forestbased project. Winrock, International. Forest Carbon Monitoring Progam, Winrock International, Airlington, VA, USA.

Daniel C. Donato, J. Boone Kauffman, Daniel Murdiyarso, Sofyan Kurnianto, Melanie Stidham and Markku Kanninen. (2011). Mangroves among the most carbonrichforests in the tropics. Nature Geoscience. DOI: 10.1038

Iswandar, Meivi., Irma, D dan Viqqi Kurnianda. (2017). Dugaan serapan karbon pada vegetasi mangrove di kawasan mangrove Gampong Iboih, kecamatan Sukakarya, Kota Sabang. Jurnal IImiah Mahasiswa Kelautan dan Perikanan Unsyiah, 2(4), 512-518.

Munari, S. (2011). Teknik pendugaan cadangan karbon. Merang Redd Pilot Project- German International Cooperation. Palembang.

Sadelie, A., Kusumastanto, T., Kusmana, C., Hardjomidjojo, H. (2012). Kebijakan pengelolaan sumberdaya pesisir berbasis perdagangan karbon. Jurnal Hutan dan Masyarakat, 6(1), 1-1

Soemarwoto, O. (1998). Ekologi lingkungan hidup dan pembangunan. Djambatan. Bandung. 